\title{
ISLAMIC, GREEN, AND CONVENTIONAL CRYPTOCURRENCY MARKET EFFICIENCY DURING THE COVID-19 PANDEMIC
}

\author{
Emna Mnif ${ }^{1}$ and Anis Jarboui ${ }^{2}$ \\ ${ }^{1}$ Sfax University, Tunisia, emna.mnif@fsegs.usf.tn, emnamnifmasmoudi@gmail.com \\ ${ }^{2}$ Sfax University, Tunisia, anisjarboui@yahoo.fr
}

\begin{abstract}
Unlike conventional cryptocurrencies, Islamic ones are new technologies backed by tangible assets and are characterised by their fundamental values. After the COVID-19 outbreak, cryptocurrency responses have shown different behaviour to stock market reactions. However, there is a lack of studies on the efficiency of Islamic and green cryptocurrencies during the pandemic. This paper attempts to analyse the behaviour of three typical families of cryptocurrencies (conventional, Islamic, and green) extracted according to their availability in daily frequencies during COVID-19. For this purpose, their efficiency levels are studied before and after the outbreak by employing multifractal detrended fluctuation analysis (MFDFA) to make the best predictions and strategies. The inefficiency of the cryptocurrencies is assessed through a magnitude of long-memory (MLM) efficiency index, and the impact of COVID-19 on their efficiency is evaluated. The primary results show that HelloGold was the most efficient market before the COVID-19 outbreak and that subsequently Ethereum has been the most efficient. In addition, the findings reveal that the cryptocurrency reactions are not similar and show more resilience in the Ethereum and Litecoin markets than in other cryptocurrency markets. The main contribution of this study is the evaluation of the impact of COVID-19 on the various classes of crypto money. This work has practical implications, as it provides new insights into trading opportunities and market reactions. Moreover, the work has theoretical implications based on its evaluation of three distinct models from different doctrine viewpoints.
\end{abstract}

Keywords: Islamic cryptocurrencies, Covid-19, Efficiency, MFDFA.

JEL Classification: G10; G14; G15.

Article history:

Received : October 1, 2020

Revised : January 15, 2021

Accepted : Februay 8, 2021

Available online : March 31, 2021

https://doi.org/10.21098/jimf.v7i0.1315 


\section{INTRODUCTION}

\subsection{Background}

In less than three months, COVID-19 has been transformed from a simple ordinary viral epidemic into a global pandemic, threatening all the world. Despite all the negative aspects of the spread of the disease across industries, it is safe to say that many markets will be able to survive this difficult time and even profit from it (Mnif, Jarboui, \& Mouakhar, 2020). There is no doubt that the shadow of a global recession has emerged in these uncertain times. In the long term, the cryptocurrency market may not be seriously affected by these upheavals, although will not be spared, especially in the near future. Nevertheless, the quarantines imposed in many countries around the world could paradoxically generate a bullish effect on the cryptocurrency market, unlike the rest of the stock market (Ji, Zhang, \& Zhao, 2020). Many experts have described cryptocurrency markets as safe ones (Kristoufek, 2020). They have also pointed out that they can be identified as a good option for long-term investments, as their value continues to grow. It will therefore be necessary to verify whether these analyses materialise in the Islamic and green cryptocurrency markets.

Islamic cryptocurrencies are new technologies based on tangible gold or currencies. The technological applications have exploited existing blockchains to meet the religious needs of some investors. OneGram was the first cryptocurrency to be certified by Al Maali Consulting in compliance with established Islamic rules. Each OneGram coin is backed by at least one gram of physical gold, which provides a stable floor price. HelloGold was certified by Amanie Advisors ${ }^{1}$, while the X8X currency was certified by the Shariyah Review Bureau (SRB); the latter offers an alternative to valuing the preservation of assets. It is backed by a basket of eight currencies and gold to fight inflation, whilst remaining fully liquid and cash-backed.

Unlike conventional cryptos, these Islamic technologies involve financially quantifiable fundamentals that uphold their valuations (Berentsen \& Schär, 2018). Transaction facilitation was considered to be a driver of cryptocurrency demand, leading to investment and speculative matters in this market (Corbet, Lucey, Urquhart, \& Yarovaya, 2019). Conventional cryptocurrencies are considered to be mainly speculative, as cash money does not underlie their value (Böhme, Christin, Edelman, \& Moore, 2015). From the behavioural perspective, cryptocurrencies develop a large volume of data that visualises investors' preferences (Böhme, Christin, Edelman, \& Moore, 2015). In 2018, most investors were deemed to be buy-hold miners because of the crypto assets' bearishness (Vidal-Tomás, Ibáñez, \& Farinós, 2019). The lack of financial fundamental valuation makes cryptocurrency subject to sentiment analysis and behavioural bias, such as herding behaviour (Kaiser \& Stöckl, 2019).

Herding behaviour is defined by Banerjee (1992) as the action of doing what others are doing without using one's own information. This behaviour bias leads to excessive volatility in financial markets, with short term trends (Humayun Kabir \& Shakur, 2018). Consequently, speculative bubbles and crashes are created

1 The fatwa is detailed in this link: https://help.hellogold.com/en/wp-content/uploads/2017/02/ HelloGold-Fatwa.pdf 
from repeated behavioural scenarios. Herding bias in finance can be caused by unintentional behaviour triggered by events which make traders and investors sell and buy the same asset simultaneously (Lakonishok, Shleifer, \& Vishny, 1992). In the same way, this bias can be linked to intentional factors such as informational cascades (Avery \& Zemsky, 1998) and reputational concerns (Scharfstein \& Stein, 1990).

Forbes \& Rigobon (2002) found that the investor bias generated by herding behaviour, the lack of confidence, and high levels of uncertainty provide excessive co-movement. Such behaviour is classified as both rational (Orléan, 1992) and non-rational, and both market-wide (Henker, Henker, \& Mitsios, 2012) and group-wide (Lillo, Moro, Vaglica, \& Mantegna, 2008). Previous studies have captured market-wide herding through the relationship between cross-sectional dispersion and stock returns (Christie \& Huang, 1995). In addition, Hwang and Salmon (2004) proposed a novel approach based on the cross-sectional dispersion of betas. Lakshman, Basu, and Vaidyanathan (2013) and Chen (2013) estimated herding behaviour using the dispersion of betas and found that such behaviour is a result of sentimental and psychological components, rather than macro factors. Consequently, they showed that this behaviour is less widespread during periods of market stress.

Several previous studies have paid particular attention to stock markets (Aslam, Aziz, Nguyen, Mughal, \& Khan, 2020) in examining inefficiency levels during the COVID-19 pandemic, using multifractal detrended fluctuation analysis. Some recent empirical works have studied this behaviour in the emerging cryptocurrency markets; for example, Ballis and Drakos (2019). By analysing daily data, their results show evidence that cryptocurrency investors imitate each other without and act irrationally. They attribute this behaviour to the lack of cryptocurrency fundamentals. The presence of herding behaviour in Islamic markets has been justified by Mnif, Salhi, and Jarboui (2019) and has been partially proved by Chaffai and Medhioub (2018) in some stock markets.

\subsection{Objective}

To the best of our knowledge, the efficiency of Islamic cryptocurrencies compared with green and conventional cryptocurrency markets during the COVID-19 pandemic has yet to be evaluated, despite its importance. For this reason, the dynamics of Islamic, green, and conventional cryptocurrencies are investigated in this study to compare their evolution over time and to evaluate the impact of the pandemic on their efficiency. The study investigates which kind of cryptocurrency has been more resilient during the pandemic. Our contributions can be summarised as follows. First, the paper examines the expected persistence of the cryptocurrencies using MFDFA analysis. The second contribution is the study and comparison of the degrees of inefficiency using a sample of three families of cryptocurrency. Finally, the study explores the influence of the COVID-19 disease on cryptocurrency market outcomes and dynamics.

The remainder of the paper is organised as follows. In the second section, a summary of the literature review is presented. The data are described in the third section, and the methodology discussed in the fourth section. The empirical results are considered in the fifth section, with the conclusions drawn in the final section. 


\section{LITERATURE REVIEW}

\subsection{Background Theories}

\subsubsection{Multifractal Detrended Fluctuation Analysis}

In this paper, we used the theory of multifractal detrended fluctuation analysis to assess the efficiency of each cryptocurrency. Multifractal geometry is an extension of fractal geometry in mathematical measurements (Harte, 2001). By extension, multifractal measurements respect the scale invariance property (Davies, Bennie, Inger, \& Gaston, 2013). The passage from a set of points to a measure leads to a complexification of scaling behaviours (Jørgensen \& Kokonendji, 2011). In a usual fractal, only one scaling behaviour governs its shape. However, with a multifractal measurement, rather than having a single scaling behaviour, we observe a multitude of intermixed ones (Movahed, Jafari, Ghasemi, Rahvar, \& Tabar, 2006). To describe this plurality of scaling behaviours, a single fractal dimension is insufficient, so researchers need to resort to more sophisticated tools.

The first approach consists of using generalised fractal dimensions (Barunik \& Kristoufek, 2010), while the second is based on the evaluation of a multifractal spectrum (Meneveau \&Sreenivasan, 1987). In practice, for a large class of multifractal objects, these two approaches are equivalent and we go from one to the other from a Legendre transform. In multifractal geometry, as in classical fractal geometry, the notion of dimension is plural. In the literature, there are mainly two types of measurement: dimensions related to the so-called box-counting dimensions, and those related to the Hausdorff (1918) dimension (Schwarzenberger \& Falconer, 1990). Only dimensions related to the Hausdorff (1918) dimension exist for all measurements. But in practice, only the dimensions related to the so-called "boxcounting" dimensions can be calculated. The box-counting multifractal dimension is defined as a passage to the limit of Rényi's entropy (Jizba \& Arimitsu, 2004). In finance, these models, developed by Calvet and Fisher (2008), are useful in measuring market risks. In this paper, we use this approach to focus on the efficiency of Islamic, green, and conventional cryptocurrencies, as it is helpful in making comparisons between them. Mandelbrot (1975) defined fractals as complex geometrical bodies with one feature of scaling embedded within them. They are employed in finance to detect crashes and crises. We use the same notations as those employed in the study of Mnif et al. (2020)2.

\subsubsection{Cryptocurrency Models and Doctrinal Views}

In Islamic monetary philosophy, money is not traded and has no intrinsic value. It is only considered for exchange. Earning profit through the trading of money is prohibited in Islam (Omar, 2011). In the conventional view, however, money is a commodity besides being a medium of exchange and store of value. Therefore, it can be sold at a price higher than its face value and it can also be rented out. In addition, the time value is the basis for charging interest on capital (Keynes, 2017). Profit on the trade of goods, or charging for providing services, is the basis for earning profits (Siswantoro, Handika, \& Mita, 2020).

2 For more details about the MFDFA approach, refer to the work of Mnif et al. (2020). This approach is based on five steps. In the first step, the cumulative sum or the profile is identified. In the second step, this profile is divided into segments of equal length. We then estimate the trend in the third step and average the segments in the fourth. Finally, we identify the scaling of the fluctuation function. 
Wilson (2019) argues that there are no Sharia objections to bitcoin for payments and receipts, but it is important that investors understand the risks involved. In fact, Islamic doctrine first declares that cryptocurrencies conform with the prohibition of riba (usury). Second, they incorporate principles of maslaha and mutual risksharing. Third, they can potentially be used as a parallel currency (with fiat) and as a hedging tool to protect wealth and investment (Choudhury, 2018). Despite these benefits, cryptocurrencies involve some major characteristics which do not conform with ethical and Islamic views. The green doctrine considers that cryptocurrencies consume an enormous volume of energy, which is responsible for carbon release. For this reason, experts in the blockchain industry have created "Bitcoin Green" to reduce environmental pollution and save the planet (Jacquet \& Mans, 2019).

The Islamic doctrine considers that cryptocurrencies are volatile and lack regulatory bodies. In addition, they are not backed by physical assets which provide a stable floor price, and have the potential for abuse. For these reasons, Islamic cryptocurrencies have been created to deal with such issues. As a part of these innovations, we have chosen HelloGold and X8X cryptocurrency data to study their behaviour and compare their volatilities before and after the COVID-19 pandemic.

\subsection{Previous studies}

Studying market stability and efficiency is vital for the safety and security of investments. The risk of bubbles generated by the herding behaviour of investors can be a source of market instability during certain periods. Previous models on Gaussian distribution lack robustness in predicting market inefficiency, so multifractal models were developed by Mandelbrot (1975) to address this gap. Mandelbrot defined fractals as complex geometrical bodies with one feature of scaling embedded within them. They are employed in finance to detect crashes and crises. In 1997, Mandelbrot created a multifractal model to identify the price variation of financial assets. In 2009, multifractal detrended fluctuation was proposed by Kantelhardt (2009) to identify the statistical characteristics of stochastic series over different time scales (Winsor, 1995; Blanco Rivero, 2019). In Islamic market analysis, MFDFA was investigated by Mensi, Hammoudeh, AlJarrah, Sensoy, \& Kang (2017) to detect the efficiency level of sectoral stock markets. Their results show moderate efficiency in the short term and a high level in the long term. These markets become inefficient after financial crises. On the other hand, Lahmiri, Bekiros, \& Bezzina (2020), compared the nonlinearity patterns of three cryptocurrency families (green, Islamic, and conventional), finding that long-term fluctuations were anti-persistent for all kinds of cryptocurrencies, while short term fluctuations were chaotic.

On the other hand, the influence of COVID-19 on cryptocurrency markets has been explored in many studies (Mnif, Jarboui, \& Mouakhar, 2020; Ji, Zhang, \& Zhao, 2020). These have found that cryptocurrencies have performed during the COVID-19 pandemic compared to other stock markets.

The effect of the pandemic was also investigated by Lahmiri and Bekiros (2020) in terms of the instability of cryptocurrency markets. They applied the Largest Lyapunov Exponent (LLE) measure based on Rosenstein's method and 
approximate entropy (ApEn) on a sample of 45 cryptocurrencies during the pandemic to assess the stock market and the instabilities and irregularities of cryptocurrencies.

Ji et al. (2020) evaluated cryptocurrencies, gold, commodities, and foreign exchanges to choose a suitable asset considered as a safe haven. Market anomalies caused by the COVID-19 pandemic were also explored by Yarovaya, Matkovskyy, and Jalan (2020) to detect herding behaviour in cryptocurrency markets.

To the best of our knowledge, no empirical work has compared the efficiency and herding behaviour of the three families of cryptocurrencies referred to in this study. Accordingly, the research contributes to the previous work by investigating the impact of COVID-19 on these cryptocurrencies in order to establish safe-haven markets during the pandemic. The implications of the analysis are essential for cryptocurrency traders and policy-makers in analysing and forecasting the behaviour of financial market outcomes during the coronavirus epidemic period.

\section{METHODOLOGY}

\subsection{Data}

The sample consists of three families of cryptocurrency as detailed in Table 1 extracted in daily frequencies according to their availability from www. coinmarketcap.com. The data periods were retrieved with the maximum available length because the multifractal approach needs a long period of data. The length in this case is sufficient to apply the MFDFA approach, as employed by López and Contreras (2013).

Table1.

Data Description

\begin{tabular}{lccc}
\hline \multicolumn{1}{c}{ Type } & Cryptocurrency & Start date & End date \\
\hline \multirow{2}{*}{ Islamic } & X8X & August $6^{\text {th }}, 2018$ & December $23^{\text {rd }}, 2020$ \\
& HelloGold & October $12^{\text {th }}, 2017$ & December $23^{\text {rd }}, 2020$ \\
\hline Green & Bitcoin Green & May $22^{\text {nd }}, 2018$ & December $23^{\text {rd }}, 2020$ \\
\hline \multirow{4}{*}{ Conventional } & Bitcoin & April $29^{\text {th }}, 2013$ & December $23^{\text {rd }}, 2020$ \\
& Ethereum & August $7^{\text {th }}, 2015$ & December $23^{\text {rd }}, 2020$ \\
& Ripple & August $4^{\text {th }}, 2013$ & December $23^{\text {rd }}, 2020$ \\
& Litecoin & April $29^{\text {th }}, 2013$ & December $23^{\text {rd }}, 2020$ \\
\hline
\end{tabular}

\subsection{Model Development}

The financial series present several properties which have been grouped into stylised facts. Among these properties, the existence of tails of thick distributions (leptokurticity) and the presence of long memory in volatility are particularly notable. Since the studies conducted by Mandelbrot (1963) and Fama (1965), it has been well known that financial series are leptokurtic; that is, they have a high kurtosis coefficient. Therefore, extreme values have a significant probability of occurring. This property cannot be understood from the standard modelling of financial markets based on the normality assumption of asset profitability. Another important property was highlighted in the work of Kinsella and Taylor 
(1987) and concerns the hyperbolic decrease in the autocorrelation function of the volatility of financial series. In other words, the consequences of a shock on volatility persist, as the volatility of stock market returns has a long memory. In addition, the autocorrelations are positive, which implies that high volatility observed at date $\mathrm{t}$ - 1 generates a high probability of observing high volatility at date t. This phenomenon is called clustering of volatility or simply clustering (Narayan, Narayan, Popp, \& D'Rosario, 2011). In order to take these properties into account, several modelisations have been proposed. The most commonly used models for modelling the volatility of financial series are GARCH (Generalized Autoregressive Conditional Heteroscedasticity) models. An alternative is to resort to multifractal measures. The scale function $\tau($.$) is the main tool for detecting the$ multifractal character of a series presented. When the scale function is linear, the corresponding processes are called unifractals; otherwise, they are multifractal processes (Fillol, 2005). Therefore, a multifractal process is characterised mainly by the existence of scale relations between the moments of the process. In order to study the scale properties of multifractal processes, two tools are used: Hölder exponents and the multifractal spectrum (Struzik, 1999). The multifractal spectrum boils down to one point if the process has a scale relationship and more than one point if the process has multiple scale relationships. Therefore, from the scale function and the multifractal spectrum, we can determine whether a series is multifractal. Once multifractality is detected, it is possible to model the studied series by estimating the partition function and the parameters of the scale function. We computed the partition function for different moments $q: q=\{-5 ; 0 ; 5\}$. From the partition function, we estimated the scale function of the cryptocurrency returns. By comparing the estimates of the Hurst exponent to the value of 0.5 , we can judge for the degree of persistence of the studied series (Kantelhardt, 2015).

\subsection{Method}

In this empirical section, we use fractal theory to assess the inefficiency of the studied markets before and after the COVID-19 outbreak. To estimate the MFDFA parameters, we set the following five steps (Tiwari, Aye, \& Gupta, 2019):

$x_{i}$ is a time series of length $\mathrm{N}$; i ranges from 1 to $\mathrm{N}$.

The daily returns of the corresponding cryptocurrencies are defined as (Benbachir \& El Alaoui, 2011):

$$
\mathrm{r}_{\mathrm{t}}=\log \left(\frac{p_{t}}{p_{t-1}}\right)
$$

In step 1, we identified the profile or cumulative sum Y(i) (Takaishi, 2020):

$$
\mathrm{Y}(\mathrm{i})=\sum_{k=1}^{i}|x(k)-\bar{x}|,
$$

$\bar{x}$ denotes the mean value of the whole series $\left(\bar{x}=\frac{1}{N} \sum_{i=1}^{N} x_{i}\right)$. This process converts a white noise process into a random walk.

Step 2 consisted of dividing profile $Y_{t}$ into $N_{s} \equiv \frac{N}{S}$ segments of equal lengths (Chen \& Yu, 2011). 
In the next step, the local trend was estimated by least-square fitting polynomial $\widetilde{Y}_{v}$ for any segment of length (Kukacka \& Kristoufek, 2020):

$$
F_{s}^{2}(v)=\frac{1}{s} \sum_{k=1}^{s}\left(Y_{v}(k)-\widetilde{Y}_{v}(k)\right)^{2}
$$

This detrending process was repeated over a range of various window sizes s.

In the fourth step, we averaged the segments to draw the $\mathrm{q}^{\text {th }}$ order fluctuation function $\mathrm{F}_{\mathrm{q}}$ (Kukacka \& Kristoufek, 2019):

$$
F_{q}(S)=\left\{\frac{1}{2 N_{S}} \sum_{v=1}^{2 N_{s}}\left[F_{S}^{2}(v)\right]^{\frac{q}{2}}\right\}^{\frac{1}{q}}
$$

where $\mathrm{q}$ is different from zero.

In the final step, the scaling behaviour of the fluctuation functions was identified by plotting the log-log plots of $F_{q}(s)$ for each value of $q$ versus s (Ihlen, 2012):

$$
F_{q}(S) \propto S^{H(q)}
$$

We chose to set the order at $\mathrm{m}=1$ to avoid overfitting problems (Lashermes, Abry, \& Chainais, 2004).

We then estimated the generalised Hurst exponent, as employed by Mnif et al. (2020). Subsequently, we calculated the inefficiency index, the magnitude of longmemory (MLM).

The inefficiency index based on the multifractal dimension indicated that the fluctuations comprising smaller $\mathrm{H}(-5)$ and larger $\mathrm{H}$ (5) followed the random walk process.

In other words, when MLM=0 the volatilities of these cryptocurrency returns are absolutely efficient with no long memory and no herding behaviour.

Accordingly, a higher (or lower) value of MLM indicates a higher (or lower) level of long memory and a higher level of herding behaviour in the volatility of the cryptocurrency returns. Finally, efficiency and the herding levels were tested using the inefficiency index (MLM), as suggested by Khuntia and Pattanayak (2020), denoted as:

$$
(\mathrm{MLM})=\frac{1}{2}(|\mathrm{~h}(-5)-0.5|+|\mathrm{h}(5)-0.5|)
$$

\section{RESULTS AND ANALYSIS}

\subsection{Results}

The width of the fractal spectrum $\Delta \alpha$ represents the difference between the upper and the lower probabilities, as shown in Table 2. Multifractality increases when $\Delta \alpha$ is expanded (Lu, Tian, Zhou, \& Li, 2013). 
Table 2.

Multifractality Results before and after the COVID-19 Outbreak

\begin{tabular}{lccccccc}
\hline \multirow{2}{*}{ Cryptocurrency } & & Hq & $\begin{array}{c}\text { Hurst } \\
\text { Average }\end{array}$ & $\begin{array}{c}\text { Fractal } \\
\text { Dimension (d) }\end{array}$ & MLM & Ranking \\
\hline \multirow{2}{*}{ Hello Gold (HGT) } & Before & Before & 0.0599 & 0.4508364 & 1.549164 & 0.02995 & 1 \\
& After & After & 0.2369 & 0.3984091 & 1.601591 & 0.11845 & 3 \\
\hline \multirow{2}{*}{ X8X } & Before & Before & 0.5488 & 0.3570273 & 1.642973 & 0.2744 & 7 \\
& After & After & 0.6395 & 0.4371909 & 1.562809 & 0.31975 & 7 \\
\hline \multirow{2}{*}{ Bitcoin Green (BITG) } & Before & Before & 0.2378 & 0.5872182 & 1.412782 & 0.1189 & 2 \\
& After & After & 0.3931 & 0.4618273 & 1.538173 & 0.19655 & 4 \\
\hline \multirow{2}{*}{ Bitcoin (BTC) } & Before & Before & 0.2895 & 0.66809091 & 1.331909 & 0.18235 & 3 \\
& After & After & 0.4582 & 0.6406909 & 1.359309 & 0.2291 & 5 \\
\hline \multirow{2}{*}{ Ethereum (ETH) } & Before & Before & 0.3215 & 0.7002818 & 1.299718 & 0.18615 & 5 \\
& After & After & 0.1585 & 0.6009182 & 1.399082 & 0.07925 & 1 \\
\hline \multirow{2}{*}{ Ripple (XRP) } & Before & Before & 0.3724 & 0.65653636 & 1.343464 & 0.18595 & 4 \\
& After & After & 0.4472 & 0.6269727 & 1.373027 & 0.2236 & 6 \\
\hline \multirow{2}{*}{ Litecoin (LTC) } & Before & Before & 0.5485 & 0.72150909 & 1.278491 & 0.27425 & 6 \\
& After & After & 0.0818 & 0.6034273 & 1.396573 & 0.0995 & 2 \\
\hline
\end{tabular}

The interpretation of the self-similarity $(\mathrm{H})$ results is different from self-affinity $(\alpha)$. In the case of self-similarity, the series grows symmetrically in all possible directions. However, the growth in the case of self-affinity is not symmetric and is non-uniform across the series (Ghosh \& Kozarevic, 2019).

In an efficient market, the dynamics of the fluctuations should follow random walk behaviour and $\mathrm{Hq}()$ is equal to 0.5 . For this reason we computed the inefficiency index (MLM) based on $\mathrm{Hq}($ ), as presented in Table 2, which is close to zero for an efficient market. In other words, the larger this index (MLM) is, the less efficient the market.

The results in Table 2 show that all of the inefficiency values (MLM) are lower than 0.5 and higher than 0.02995 , indicating that all of the cryptocurrencies are almost efficient, with different degrees of efficiency. The closest value of the inefficiency index (MLM) to zero corresponds to HelloGold before the COVID19 outbreak. However, Ethereum was found to be the most resilient and most efficient after the outbreak. This cryptocurrency is therefore the most tempting for both speculators and traders. In the same way, the deviation level of the inefficiency index (MLM) from zero draws the intensity of the herding bias in these markets.

Recent studies have linked fractal theory to Hausdorff topology (Hausdorff, 1918) to judge for the presence and level of herding and other heuristics biases (Ghosh \& Kozarevic, 2019). In fact, herding behaviour increases when the shape moves from the Douady rabbit (with a fractal dimension $\mathrm{d}=1.4$ and $\mathrm{d}=1.38$ ) to a five circle inversion fractal $(\mathrm{d}=1.36)$, finally reaching the Dendrite Julia $(\mathrm{d}=1.18)$ and contour of the Gosper Island ( $\mathrm{d}=1.12)$. In other words, the presence of herding behaviour is justified when $\mathrm{d}$ varies between 1.12 and 1.4. 
In Table 2, the Hurst average and the fractal dimension are associated with $\mathrm{q}$ values ranging from -5 to 5 . The results reported in this table show that:

- In the Islamic and green cryptocurrency markets, the fractal dimension is upper 1.4, indicating the absence of herding behaviour in these markets in both sub-periods (before and after the outbreak).

- In the case of Bitcoin and Ripple, the fractal dimension d is around 1.36, corresponding to five circle inversion fractal in both periods and showing a moderating level of herding behaviour. These findings are in line with those of previous studies (Ballis \& Drakos, 2019). Moreover, the fractal dimension $\mathrm{d}$ increases between the first sub-period (before the outbreak) and the second (after the outbreak), implying that herding behaviour decreases between the two periods. These empirical findings are also in line with previous works (Stavroyiannis \& Babalos, 2019). Therefore, the risk of bubbles weakens and inefficiency is minimised.

- In the case of the Ethereum and Litecoin markets, the fractal dimension $\mathrm{d}$ varies between the five circle inversion fractal $(\mathrm{d}=1.36)$ and the Dendrite Julia $(d=1.18)$ in both periods, showing the greatest level of the herding behaviour. In addition, the fractal dimension increases between the first sub-period (before the outbreak) and the second (after the outbreak), indicating that herding behaviour declines during these periods. These results are in accordance with previous studies (Celeste, Corbet, \& Gurdgiev, 2020); consequently inefficiency is reduced and bubble risks are minimised.

Therefore, herding behaviour decreased in conventional, showing that the COVID-19 pandemic has had a positive impact on the other studied cryptocurrencies.

\subsection{Analysis}

All the selected cryptocurrency markets have been found to be inefficient, which is as expected and is line with most studies on cryptocurrency efficiency (Kristoufek \& Vosvrda, 2019; Wei, 2018; Hu, Valera, \& Oxley, 2019). The Islamic cryptocurrency HelloGold was the least inefficient before the COVID-19 outbreak. Consequently, it is the least risky of the cryptocurrency markets. These findings follow previous analyses of Islamic markets, such as the study of Sorwar, Pappas, Pereira, and Nurullah (2016). The results can be explained by the fact that Islamic cryptocurrencies are distinguished from conventional ones by their fundamental value, as they are backed by tangible assets. However, Islamic and green cryptocurrencies have been found to be vulnerable to the COVID-19 pandemic, as they became less efficient after its outbreak. In fact, the results can be explained by the fact that they are less potent in terms of trading volume and market capitalisation. In other words, investors are focusing on potential markets to purchase cryptocurrencies. This signifies that in periods of crisis, investors focus on saving their money, which is why the behaviour of these cryptocurrencies changed after the COVID-19 outbreak.

The primary results show that all of the cryptocurrency families are inefficient. For this reason, we have focused on the presence of certain behavioural biases, such as herding. The results reveal the lack of such bias in both Islamic and green markets during both calm and crisis periods. These results are contrary to the 
findings of Mnif et al. (2019) and Chaffai and Medhioub (2018), who demonstrated the existence of herding behaviour in Islamic stock markets. Therefore, investors' views of Islamic stock market investments are different from those of cryptocurrency markets.

Furthermore, our findings demonstrate the presence of herding behaviour in conventional markets and indicate that this bias was reduced after the outbreak. The results are in line with previous studies, such as those of Bouri, Gupta, and Roubaud (2019), who proved the presence of such behaviour in cryptocurrency markets, and the work of Yarovaya et al. (2020), who found that the COVID-19 pandemic reduced the presence of this bias. The presence of herding behaviour can be attributed to the existence of irrational investors or non-professional institutions. It can also be caused by the lack of fundamental value, which could be a source of market bubbles.

\section{CONCLUSION AND RECOMMENDATIONS}

\subsection{Conclusion}

This paper has studied the efficiency level, and detected the existence, of herding behaviour in three families of cryptocurrency markets using the generalised Hurst exponent as an evaluation measurement of fractality and employing the multifractal fractal detrended fluctuation approach. The empirical results of the GHE estimation indicate that most cryptocurrencies were multifractal before and after the COVID-19 outbreak. In addition, Islamic cryptocurrency markets are not efficient and were anti-persistent before and after the COVID-19 outbreak, as also found by Lahmiri and Bekiros (2019). On the other hand, HelloGold was found to be the least inefficient of the selected cryptocurrencies. The conventional and green cryptocurrencies were inefficient and displayed multifractal behaviour. These findings are in line with other empirical findings (Conlon, Corbet, \& McGee, 2020) and are suitable for the general expectations of most cryptocurrency markets. For more robust results, we measured cryptocurrency efficiency using an index of the magnitude of long-memory to rank them according to their efficiency. The results clearly show that HelloGold was the most efficient before the COVID-19 pandemic; however, Ethereum was the most efficient after the outbreak. Based on the inefficiency results, this study has investigated the presence of herding behaviour to detect market anomalies and prevent the risk of bubbles. The results demonstrate the lack of herding behaviour in the Islamic and green cryptocurrency markets. Despite the presence of this bias in conventional markets, the study findings prove that the COVID-19 pandemic has reduced such behaviour.

\subsection{Recommendations}

By using an inefficiency index, the markets have been ranked and classified in terms of their efficiency and risk level, which may help cryptocurrency traders to develop their trading strategies. In other words, investors who prefer risk are more oriented towards risky cryptocurrencies, while others who avoid risk and seek stable markets will select the most efficient ones. Moreover, the analysis of the COVID-19 effect on cryptocurrency markets has classified them as vulnerable or resilient to shocks, which can be helpful in developing monetary policy and making trading decisions. 
Unlike political and social occurrences such as wars, the recent outbreak of COVID19 is a biological disaster that damages human health and the economic sphere, leading to spillover and market reaction. The empirical results of the study show that the pandemic has disturbed the cryptocurrency market at different levels. The Islamic cryptocurrency HelloGold presents the least risk among the markets studied before COVID-19. However, the Ethereum cryptocurrency has been found to be more resilient than the others in such a crisis. In other words, information on the Islamic cryptocurrencies has lacked transparency after the outbreak compared to conventional ones. However, they were found to be more transparent before the pandemic. Information on Islamic cryptocurrencies should be more available and transparent in periods of crisis to ease the decisions of policy-makers. Therefore, this empirical study may provide valuable analysis for marketers, and help them make the best decisions and strategies. In the same way, herding behaviour is nonexistent in Islamic and green markets, indicating the absence of irrational investors and traders. However, the justified presence of this bias in conventional markets shows that people are more comfortable with investing their money in the same way as the majority of others. They simply rely on the rhythm of the crowd, leading to an increase in prices and market bubbles. Accordingly, investors in Islamic and green cryptocurrency markets are more rational, which can be explained by the Islamic and ethical norms that guide these markets.

\section{REFERENCES}

Aslam, F., Aziz, S., Nguyen, D. K., Mughal, K. S., \& Khan, M. (2020). On the efficiency of foreign exchange markets in times of the COVID-19 pandemic. Technological Forecasting and Social Change, 161(December 2020), 120261. https:// doi.org/10.1016/j.techfore.2020.120261.

Avery, C., \& Zemsky, P. (1998). Multidimensional uncertainty and herd behavior in financial markets. American Economic Review, 88(4), 724-748. https:/doi. org/10.2307/117003.

Ballis, A., \& Drakos, K. (2019). Testing for herding in the cryptocurrency market. Finance Research Letters, 33(March 2020), 101210. https://doi.org/10.1016/j. frl.2019.06.008.

Banerjee, A. V. (1992). A simple model of herd behavior. The Quarterly Journal of Economics, 107(3), 797-817. https://doi.org/10.2307/2118364.

Barunik, J., \& Kristoufek, L. (2010). On hurst exponent estimation under heavytailed distributions. Physica A: Statistical Mechanics and Its Applications, 389(18), 3844-3855. https://doi.org/10.1016/j.physa.2010.05.025.

Benbachir, S., \& El Alaoui, M. (2011). A multifractal detrended fluctuation analysis of the Moroccan stock exchange. International Research Journal of Finance and Economics, 78(2011), 6-17. https://mpra.ub.uni-muenchen.de/id/eprint/49003.

Berentsen, A., \& Schär, F. (2018). A short introduction to the world of cryptocurrencies. Review, 100(1), 1-16. https://doi.org/10.20955/r.2018.1-16.

Blanco Rivero, J. J. (2019). The fractal geometry of Luhmann's sociological theory or debugging systems theory. Technological Forecasting and Social Change, 146(September 2019), 31-40. https://doi.org/10.1016/j.techfore.2019.05.020. 
Böhme, R., Christin, N., Edelman, B., \& Moore, T. (2015a). Bitcoin: Economics, technology, and governance. Journal of Economic Perspectives, 29(2), 213-238. https://doi.org/10.1257/jep.29.2.213.

Bouri, E., Gupta, R., \& Roubaud, D. (2019). Herding behaviour in cryptocurrencies. Finance Research Letters, 29(June 2019), 216-221. https://doi.org/10.1016/j. frl.2018.07.008.

Calvet, L. E., \& Fisher, A. J. (2008). Multifractual volatility: Theory, forecasting and pricing. In Monographs of the Society for Research in Child Development. https:// doi.org/10.3917/fina.301.0151.

Celeste, V., Corbet, S., \& Gurdgiev, C. (2020). Fractal dynamics and wavelet analysis: Deep volatility and return properties of Bitcoin, Ethereum and Ripple. Quarterly Review of Economics and Finance, 76(May 2020), 310-324. https://doi. org/10.1016/j.qref.2019.09.011.

Chaffai, M., \& Medhioub, I. (2018). Herding behavior in Islamic GCC stock market: A daily analysis. International Journal of Islamic and Middle Eastern Finance and Management, 11(2), 182-193. https://doi.org/10.1108/IMEFM-08-2017-0220.

Chen, T. (2013). Do investors herd in global stock markets? Journal of Behavioral Finance, 14(3), 230-239. https://doi.org/10.1080/15427560.2013.819804.

Chen, Y., \& Yu, J. (2011). Efficient market hypothesis in the international oil price fluctuation: Based on the MF-DFA model. International Journal of Global Energy Issues, 35(2-4). https://doi.org/10.1504/IJGEI.2011.045023.

Choudhury, M. A. (2018). Micro-money, finance and real economy interrelationship in the framework of islamic ontology of unity of knowledge and the worldsystem of social economy. International Journal of Social Economics, 45(2), 445462. https://doi.org/10.1108/IJSE-11-2016-0340.

Christie, W. G., \& Huang, R. D. (1995). Following the pied piper: Do individual returns herd around the market? Financial Analysts Journal, 51(4), 31-37. https:// doi.org/10.2469/faj.v51.n4.1918.

Conlon, T., Corbet, S., \& McGee, R. J. (2020). Are cryptocurrencies a safe haven for equity markets? An international perspective from the COVID-19 pandemic. Research in International Business and Finance, 54(December 2020), 101248. https://doi.org/10.1016/j.ribaf.2020.101248.

Corbet, S., Lucey, B., Urquhart, A., \& Yarovaya, L. (2019). Cryptocurrencies as a financial asset: A systematic analysis. International Review of Financial Analysis, 62(March 2019), 182-199. https://doi.org/10.1016/j.irfa.2018.09.003.

Davies, T. W., Bennie, J., Inger, R., \& Gaston, K. J. (2013). Artificial light alters natural regimes of night-time sky brightness. Scientific Reports, 3(1722), 1-6. https://doi.org/10.1038/srep01722.

Fama, E. F. (1965). The Behavior of stock-market prices. The Journal of Business, 38(1), 34-105. https://doi.org/10.1086/294743.

Forbes, K. J., \& Rigobon, R. (2002). No contagion, only interdependence: Measuring stock market comovements. The Journal of Finance, 57(5), 2223-2261. https://doi. org/10.1111/0022-1082.00494.

Fillol, J. (2005). Modélisation multifractale du taux de change dollar/euro. Economie Internationale, 2005/4(n $\left.{ }^{0} 104\right), 135-150$. 
Ghosh, B., \& Kozarevic, E. (2019). Multifractal analysis of volatility for detection of herding and bubble: Evidence from CNX Nifty HFT. Investment Management and Financial Innovations, 16(3), 182-193. https://doi.org/10.21511/imfi.16(3).2019.17.

Harte, D. (2001). Multifractals: Theory and applications. Florida: Chapman \& Hall/ CRC.

Hausdorff, F. (1918). Dimension und äußeres Maß. Mathematische Annalen, 79(March 1918), 157-179. https://doi.org/10.1007/BF01457179.

Henker, J., Henker, T., \& Mitsios, A. (2012). Do investors herd intraday in the Australian equities market? SSRN Electronic Journal. Availabe at : https://doi. org/10.2139/ssrn.482202.

Hu, Y., Valera, H. G. A., \& Oxley, L. (2019). Market efficiency of the top market-cap cryptocurrencies: Further evidence from a panel framework. Finance Research Letters, 31(December 2019), 138-145. https://doi.org/10.1016/j.frl.2019.04.012.

Humayun Kabir, M., \& Shakur, S. (2018). Regime-dependent herding behavior in Asian and Latin American stock markets. Pacific Basin Finance Journal, 47(February 2018), 60-78. https://doi.org/10.1016/j.pacfin.2017.12.002.

Hwang, S., \& Salmon, M. (2004). Market stress and herding. Journal of Empirical Finance, 11(4), 585-616. https://doi.org/10.1016/j.jempfin.2004.04.003.

Ihlen, E. A. F. (2012). Introduction to multifractal detrended fluctuation analysis in Matlab. Frontiers in Physiology, 3(June 2012), 141. https://doi.org/10.3389/ fphys.2012.00141.

Jacquet, P., \& Mans, B. (2019). Green mining: Toward a less energetic impact of cryptocurrencies. INFOCOM2019-IEEE Conference on Computer Communications Workshops, INFOCOM WKSHPS 2019. Available at: https://doi.org/10.1109/ INFCOMW.2019.8845233.

Ji, Q., Zhang, D., \& Zhao, Y. (2020). Searching for safe-haven assets during the COVID-19 pandemic. International Review of Financial Analysis, 71(October 2020), 101526. https://doi.org/10.1016/j.irfa.2020.101526.

Jizba, P., \& Arimitsu, T. (2004). The world according to Rényi: Thermodynamics of multifractal systems. Annals of Physics, 312(1), 17-59. https://doi.org/10.1016/j. aop.2004.01.002.

Jørgensen, B., \& Kokonendji, C. C. (2011). Dispersion models for geometric sums. Brazilian Journal of Probability and Statistics, 25(3), 263-293. https://doi. org/10.1214/10-BJPS136.

Kaiser, L., \& Stöckl, S. (2019). Cryptocurrencies: Herding and the transfer currency. Finance Research Letters, 33(March 2020), 101214. https://doi.org/10.1016/j. frl.2019.06.012.

Kantelhardt, J. W. (2009). Fractal and Multifractal Time Series. In: Meyers R. (eds) Encyclopedia of Complexity and Systems Science. New York: Springer https://doi. org/10.1007/978-0-387-30440-3_221.

Kantelhardt, J. W. (2015). Fractal and Multifractal Time Series. In: Meyers R. (eds) Encyclopedia of Complexity and Systems Science. Berlin: Springer. https://doi. org/10.1007/978-3-642-27737-5_221-3.

Keynes, J. M. (2017). The General theory of employment, interest and money. In Modern Economic Classics-Evaluations Through Time. Cham: Palgrave Macmillan. https://doi.org/10.4324/9781315270548-13. 
Khuntia, S., \& Pattanayak, J. K. (2020). Adaptive long memory in volatility of intraday bitcoin returns and the impact of trading volume. Finance Research Letters, 32(January 2020), 101077. https://doi.org/10.1016/j.frl.2018.12.025.

Kinsella, A., \& Taylor, S. (1987). Modelling Financial Time Series. The Statistician, 36(4), 433. https://doi.org/10.2307/2348865.

Kristoufek, L. (2020). Grandpa, grandpa, tell me the one about Bitcoin being a safe haven: New evidence from the COVID-19 pandemic. Frontiers in Physics, 8, 296. https://doi.org/10.3389/fphy.2020.00296.

Kristoufek, L., \& Vosvrda, M. (2019). Cryptocurrencies market efficiency ranking: Not so straightforward. Physica A: Statistical Mechanics and Its Applications, 531(October 2019), 120853. https://doi.org/10.1016/j.physa.2019.04.089.

Kukacka, J., \& Kristoufek, L. (2019). Do complex financial models lead to complex dynamics? Agent-based models and multifractality. SSRN Electronic Journal. https://doi.org/10.2139/ssrn.3426341.

Kukacka, J., \& Kristoufek, L. (2020). Do 'complex' financial models really lead to complex dynamics? Agent-based models and multifractality. Journal of Economic Dynamics and Control, 113(April 2020), 103855. https://doi. org/10.1016/j.jedc.2020.103855.

Lahmiri, S., \& Bekiros, S. (2019). Decomposing the persistence structure of Islamic and green crypto-currencies with nonlinear stepwise filtering. Chaos, Solitons and Fractals, 127(October 2019), 334-341. https://doi.org/10.1016/j. chaos.2019.07.012.

Lahmiri, S., \& Bekiros, S. (2020). The impact of COVID-19 pandemic upon stability and sequential irregularity of equity and cryptocurrency markets. Chaos, Solitons and Fractals, 138(September 2020), 109936. https://doi.org/10.1016/j. chaos.2020.109936.

Lahmiri, S., Bekiros, S., \& Bezzina, F. (2020). Multi-fluctuation nonlinear patterns of European financial markets based on adaptive filtering with application to family business, green, Islamic, common stocks, and comparison with Bitcoin, NASDAQ, and VIX. Physica A: Statistical Mechanics and its Applications, 538(January 2020), 122858. https://doi.org/10.1016/j.physa.2019.122858.

Lakonishok, J., Shleifer, A., \& Vishny, R. W. (1992). The impact of institutional trading on stock prices. Journal of Financial Economics, 32(1), 23-43. https://doi. org/10.1016/0304-405X(92)90023-Q.

Lakshman, M. V., Basu, S., \& Vaidyanathan, R. (2013). Market-wide herding and the impact of institutional investors in the Indian capital market. Journal of Emerging Market Finance, 12(2), 197-237. https://doi.org/10.1177/0972652713494046.

Lashermes, B., Abry, P., \& Chainais, P. (2004). New insights into the estimation of scaling exponents. International Journal of Wavelets, Multiresolution and Information Processing, 2(4), 497-523. https://doi.org/10.1142/s0219691304000597.

Lillo, F., Moro, E., Vaglica, G., \& Mantegna, R. N. (2008). Specialization and herding behavior of trading firms in a financial market. New Journal of Physics, 10(April 2008). https://doi.org/10.1088/1367-2630/10/4/043019.

López, J. L., \& Contreras, J. G. (2013). Performance of multifractal detrended fluctuation analysis on short time series. Physical Review E-Statistical, Nonlinear, and Soft Matter Physics, 87(February 2013), 022918. https://doi.org/10.1103/ PhysRevE.87.022918. 
Lu, X., Tian, J., Zhou, Y., \& Li, Z. (2013). Multifractal detrended fluctuation analysis of the Chinese stock index futures market. Physica A: Statistical Mechanics and its Applications, 392(6), 1452-1458. https://doi.org/10.1016/j.physa.2012.11.037.

Mandelbrot, B. (1963). The variation of certain speculative prices. The Journal of Business, 36, 394-419. https://doi.org/10.1086/294632.

Mandelbrot, B. B. (1975). Stochastic models for the earth's relief, the shape and the fractal dimension of the coastlines, and the number area rule for islands. Proceedings of the National Academy of Sciences of the United States of America, 72(10), 3825-3828. https://doi.org/10.1073/pnas.72.10.3825.

Mandelbrot, B. B. (1997). The variation of certain speculative prices. In Fractals and Scaling in Finance (pp. 371-418). New York: Springer. https:/doi. org/10.1007/978-1-4757-2763-0_14.

Meneveau, C., \& Sreenivasan, K. R. (1987). The multifractal spectrum of the dissipation field in turbulent flows. Nuclear Physics B - Proceedings Supplements, 2(November 1987), 49-76. https://doi.org/10.1016/0920-5632(87)90008-9.

Mensi, W., Hammoudeh, S., Al-Jarrah, I. M. W., Sensoy, A., \& Kang, S. H. (2017). Dynamic risk spillovers between gold, oil prices and conventional, sustainability and Islamic equity aggregates and sectors with portfolio implications. Energy Economics, 67(September 2017), 454-475. https:/doi. org/10.1016/j.eneco.2017.08.031.

Mnif, E., Jarboui, A., \& Mouakhar, K. (2020). How the cryptocurrency market has performed during COVID 19? A multifractal analysis. Finance Research Letters, 36(October 2020)., 101647. https://doi.org/10.1016/j.frl.2020.101647.

Mnif, E., Salhi, B., \& Jarboui, A. (2019). Herding behaviour and Islamic market efficiency assessment: Case of Dow Jones and sukuk market. International Journal of Islamic and Middle Eastern Finance and Management, 13(1), 24-41. https://doi.org/10.1108/IMEFM-10-2018-0354.

Movahed, M. S., Jafari, G. R., Ghasemi, F., Rahvar, S., \& Tabar, M. R. R. (2006). Multifractal detrended fluctuation analysis of sunspot time series. Journal of Statistical Mechanics: Theory and Experiment, 2006(February). https://doi. org/10.1088/1742-5468/2006/02/P02003.

Narayan, P. K., Narayan, S., Popp, S., \& D’Rosario, M. (2011). Share price clustering in Mexico. International Review of Financial Analysis, 20(2), 113-119. https://doi. org/10.1016/j.irfa.2011.02.003.

Omar, M. N. (2011). The Islamic view on money and its implication to financial instruments. ISRA International Journal of Islamic Finance, 3(1), 161-168.

Orléan, A. (1992). Contagion des opinions et fonctionnement des marchés financiers. Revue Économique, 43(4), 685-697. https://doi.org/10.3406/reco.1992.409384.

Scharfstein, D. S., \& Stein, J. C. (1990). Herd behavior and investment. American Economic Review, 80(3), 465-479.

Schwarzenberger, R., \& Falconer, K. (1990). Fractal geometry: Mathematical foundations and applications. The Mathematical Gazette, 74(469), 316-317. https://doi.org/10.2307/3619861.

Siswantoro, D., Handika, R., \& Mita, A. F. (2020). The requirements of cryptocurrency for money, an Islamic view. Heliyon, 6(1), e03235. https:/doi. org/10.1016/j.heliyon.2020.e03235. 
Sorwar, G., Pappas, V., Pereira, J., \& Nurullah, M. (2016). To debt or not to debt: Are Islamic banks less risky than conventional banks? Journal of Economic Behavior and Organization, 132(Supplement), 113-126. https://doi.org/10.1016/j. jebo.2016.10.012.

Stavroyiannis, S., \& Babalos, V. (2019). Time-varying herding behavior within the Eurozone stock markets during crisis periods: Novel evidence from a TVP model. Review of Behavioral Finance, 12(2), 83-96. https://doi.org/10.1108/RBF07-2018-0069.

Struzik, Z. R. (1999). Local effective hölder exponent estimation on the wavelet transform maxima tree. In Fractals (pp. 93-112). Switzerland: Springer Link https://doi.org/10.1007/978-1-4471-0873-3_7.

Takaishi, T. (2020). Rough volatility of Bitcoin. Finance Research Letters, 32(January 2020), 101379. https://doi.org/10.1016/j.frl.2019.101379.

Tiwari, A. K., Aye, G. C., \& Gupta, R. (2019). Stock market efficiency analysis using long spans of Data: A multifractal detrended fluctuation approach. Finance Research Letters, 28(March 2019), 398-411. https://doi.org/10.1016/j. frl.2018.06.012.

Vidal-Tomás, D., Ibáñez, A. M., \& Farinós, J. E. (2019). Herding in the cryptocurrency market: CSSD and CSAD approaches. Finance Research Letters, 30(September 2019), 181-186. https://doi.org/10.1016/j.frl.2018.09.008.

Wei, W. C. (2018). Liquidity and market efficiency in cryptocurrencies. Economics Letters, 168(July 2018), 21-24. https://doi.org/10.1016/j.econlet.2018.04.003.

Wilson, R. (2019). Implications of technological advance for financial intermediation in Islamic finance. In U. A Oseni, \& S. N, Ali (Eds.), Fintech in Islamic Finance; Theory and Practice (pp. 33-46). Abingdon, Oxon: Routledge. https://doi. org/10.4324/9781351025584-3.

Winsor, R. D. (1995). Marketing under conditions of chaos. Percolation metaphors and models. Journal of Business Research, 34(3), 181-189. https://doi. org/10.1016/0148-2963(94)00115-U.

Yarovaya, L., Matkovskyy, R., \& Jalan, A. (2020). The Effects of a "Black Swan" event (COVID-19) on herding behavior in cryptocurrency markets: Evidence from cryptocurrency USD, EUR, JPY and KRW markets. SSRN Electronic Journal (April 27, 2020). https://doi.org/10.2139/ssrn.3586511. 
184 Islamic, Green, and Conventional Cryptocurrency Market Efficiency During the COVID-19 Pandemic

This page is intentionally left blank 